\title{
Characteristics of Flowering and Fruiting Description of Pomegranate (Punica granatum L.)
}

\author{
N. Varun Kumar, Ankush Godara and Anis Mirza*
}

Department of Horticulture, SAGR, Lovely Professional University, Phagwara, Punjab, India

*Corresponding author

\section{Keywords}

Hermaphrodite, Inflorescence,

Anthesis,

Juvenile period

Article Info

Accepted:

04 October 2020

Available Online:

10 November 2020

\section{A B S T R A C T}

Pomegranate a fruit of paradise (Punica granatum L.) Lythraceae family is the earliest and significant outgrowth crop of arid and Semi-arid regions all over the Globe. This has a distinctively brief developmental period of 1 - 2 years, contrasted with other perennial fruit crops since flowering results in fruiting bodies, Flower of pomegranate blooms almost throughout the year in tropical climates while in subtropics, blooming is observed only once every year. Hence, it is characterized by two styles of flowers: (hermaphrodite) bisexual flowers and functionally male flowers on the same tree. This situation, termed as functional and romonoecy. Male blossoms are directly related to minimum yields which are not capable to set fruit. The plant is deciduous in zones wherever the temperature is low during winter, even though it is mostly evergreen in a hot tropical environment. While evergreen pomegranate cultivars bloom the entire year and the inflorescence is a dichasial cyme that is urcerate, campanulate, and rounded, correspondingly. Both pin and thrum type blossoms are identified in perfect blossoms. The gender proportion changes according to seasons and concerning selection. Both allogamy and autogamy pollination happens in the fruit of paradise protogyny which occurs through Cross pollination is predictable. For proper enrichment of crops through the Hybridization method, the amount of perfect flowers of the female parent has a vital impact on pollen viability.

\section{Introduction}

Pomegranate is a major fruit crop of the world's Tropical and Subtropical regions and it's a crop of doubling farmers' income (Jyotsana Sharma et al., 2018). Seasonal floral control plays a main role in plant survival and adaptation to changes in its environment. Awareness of the control of blossoming time and the possibility of modulating it has considerable potential in fruit trees to increase their productivity as well as to expand their geographic range
(Miguel et al., 2010). Pomegranate is an economically essential fruit crop grown for its wholesome fruit and juice. In addition to the fruit, it is famous for its dietary content which is composed of anthocyanins, polyphenols, vitamins, tannins, critical organic acids, sugars, minerals, etc. In detail on various properties of medicinal and trade uses of pomegranate have been broadly summarized (Teixeira da Silva et al., 2013) and its farming is on the rise each year. It can grow to an elevation of up to 2000 meters from the plains. For the last decade, it has been an 
important export-oriented crop in India (Chandra and Jadhav et al., 2008) under a temperate zone, it acts as a deciduous plant whereas it acts as an evergreen or partly deciduous plant in subtropical and tropical climate. In India, with a yearly output of 7.5 lakh tons and a productivity of about 6.60 tons per ha, it is cultivated in over 1.20 lakh ha area. The state of Maharashtra is India's largest producer of this fruit crop. The nutritious part of the fruit is called fresh eaten arils which can be stored as syrup or used to prepare jam. Pomegranate Total area and production in India for the last three commercial years 2015 to 2018 are as follows

\section{(Horticulture Statistics 2015-2018 at a Glance by GOI)}

\begin{tabular}{|c|c|}
\hline Area (Ha) & Production (Mt) \\
\hline $\mathbf{1 9 7}$ & 2306 \\
\hline $\mathbf{2 1 6}$ & 2613 \\
\hline $\mathbf{2 3 4}$ & 2845 \\
\hline
\end{tabular}

India now ranks Top in area, production, and second in the world's overseas business of pomegranate. Over 25 variety is cultivated in various parts of India but and the main cultivars are 'Bhagwa,' 'Ganesh,' 'Mridula' and 'Phule Arakta' (Jadhav, Sharma et al., 2007) based on habitat, the crop pattern, blossoming physiology and fruiting shift (Pareek et al., 1993).

To use this beneficial function, crop control in pomegranate is practiced according to the farmer's needs and preferences (Ram asrey et al., 2007). on the other hand, it is unlucky for all of India's viable varieties which are vulnerable to critical diseases and insect pests attack, particularly airborne bacterium (Xanthomonas axonopodis) Bacterial blight, and Wilted plants due to fungus (Ceratocystis fimbriata) Jadhav Sharma et al., (2007). When together comprised posed a significant challenge majorly, Maharashtra and neighboring states which produce pomegranates since the past decade. Scientists have a difficult task of producing globally permissible major high-yielding, diseaseresistant varieties (Jadhav Sharma et al., 2007). Because a detailed understanding of flower-patterned biology is required for any crop enhancement plan (Babu et al., 2009), the so, the existing state of information on pomegranate floral biology needs to be reviewed.

\section{The flowers of pomegranate are}

Fully open, orange to red petals with various anthers attach to thick, red thread-like filaments

Single as a sitting flower and root of leathery calyx gets fuses.

Flower cluster with main inflorescence advanced in closed buds

A longitudinal segment of Hermaphrodite flowers depicting tetras of filaments discarded on the interior surface of the calyx tube

The longitudinal segment of functional male flowers with well-developed and undeveloped petioles.

Well-developed hermaphroditic flower ovaries and Functional male ovaries are underdeveloped

\section{Genes responsible for flowering}

Genes play a vital role in exhibiting their functional characters. Due to the expression of particular gene changes in vegetative and reproductive development are done

The molecular and hereditary basis of flower induction has been studied in detail in monocotyledonous and dicotyledonous crop variety. This study has recognized numerous autonomous signaling pathways to facilitate flower stimulation as well as blossoming time, 
such as vernalization, photoperiod, along with autonomic trail (Kormaed et al., 2004 and Corbusier Copland et al., 2005 and Schmid et al., 2011).

An integrated gesture of flower stimulation is transmitting to the vegetative meristem to encourage genes identifying the flower meristem of Leafy and Apetala 1 that trigger flower changeover.

Patil Hemanth B et al., (2017) reported that all genes in pomegranate show different expression patterns, which are expressed differently in vegetative bud tip and blossom sprout samples. Although the appearance of PgTFL1 (terminal 1 flowering) was low at the apex of the vegetative shoot and more in flowering, the appearance of PgCENa (Centroradialis) show the reverse model. Hence, These outcomes show the two TFL1s of the pomegranate can be used to regulate various improvement processes, specifically the suppression of $\mathrm{PgCENa}$ flowers along with the production moreover development related to the growth of PgTFL1 reproductive tissues is your expression.

Here summing up, of two TFL1 homologs, PgTFL1 along with PgCENa, which be expected to be regulated by the vegetative stage upholding embryonic plant tissue that is actively dividing and found at the tip of stem and roots which is called meristematic and their distinctiveness, blossoming activity, were isolated and characterize by imperative pomegranates in trees.

Expression observed was very less in petals, mussels; succulent buds, and fullgrown leaves, transcription of PgTFL1 was superior in young leaves and almost insignificant in full-grown leaves (Patil Hemanth et al., 2017). On the other hand, in vegetative tissues such as succulent shoot, adolescent shoot, plus leaves of fruit shoots, in these, the level of PgCENa transcription was higher than that of flower sprout, petals, and mussels. $\mathrm{PgCENa}$ appearance was more pronounced in immature leaves than in mature leaves.

These studies will facilitate understanding of pomegranate flowering behavior and regulation and will also allow for better development programs to improve pomegranate. And Patil Hemanth B et al., (2017) performed tissue and organdetailed expression patterns of $\mathrm{Pg}$ TFL1 and Pg CENa genes to examine the model of expression in Pg TFL1 and $\mathrm{Pg} \mathrm{CENa}$ genes particularly in a range of vegetative and reproductive tissues. The 2 genes showed different patterns of expression like PgTFL1 was predominantly expressed in reproductive tissues \& $\mathrm{PgCENa}$ in vegetative tissues. PgTFL1 expression was highest in fruit buds, while it was also significantly expressed among all floret sprout, shoots, and leaves. Patil Hemanth B et al., (2017)

\section{Flower-pattern}

For a detailed reading of the flowering pattern, florals were classified into various development module/setting, namely:

Narrow, unopened bud,

Emergent bud/opening bud

Open flower

Ripe flower

wilting flower (corolla)

Corolla fell off, then fruit develops

Shaded / dead

\section{Types of flowers}

The florets are small stalked or not meeting. Mainly 3 types of florets were born on the 
relative pomegranate, plant namely Antheral, Bisexual, and Intermediary (Babu et al., 2009). Hazel Y. Wetzstein, et al., (2013) performed a trial for measuring the flower size ranges from the individual and terminal flower types which are classified into four ranges of score groups which were resultant by measuring the overall flower lengths (space between the ovary base and to the direction of sepal tip) and widths (Total ovary width) in 4 parts of size based on equivalent complete scores of length. In the individual blossom forms, the floral description types were the same regardless of the Blossoming range that was based upon length or width. The midway scoring groups $(2 \& 3)$ encloses the maximum of the flowers with 30 percent coming under these middle scores. The least and prime classes had less flowers, still jointly shown for 27 percent of total blossoms. And description about terminal situated flowers they had a divided pattern using the highest number of flowers in a score of 3 , less in score 2 , and the smallest in score 1 and 4, less no of flowers fitted into the most supreme scores. The terminal flower description based on length and width were alike. though the categorization made by width changed the distributions, Hence it states that there were fewer flowers in score 3, which were again shifted to score 4 .

During the initial phase of the balloon, the floret resembles like an undersized pearshaped with a Greenish color on the initial part of it along with a flat red color lying on top or completely dark red. Staminate blossoms are "bell-shaped" though hermaphrodite flowers are "vase-shaped" The intermediary one is "Tubular". During the time of fruit harvest in these flowers, they might drop before maturing, Although some mature fruits do not have a uniform shape and the ovary of the male flower is vestigial as the medium-sized flowers degenerate Preferably bisexual flowers have developed a welldefined ovary with a broad base and often bear good fruits. The hermaphrodite flower type has a significantly longer and wider flower than the male and medium flower type. This results in a much larger ovary and a longer pistil. Mars (2000) describes the male flower type as "bell-shaped" while the hermaphrodite as "vase-shaped".

Wetzstein et al., (2011), the "male" flower of the "beautiful" variety reported being $2.7 \mathrm{~cm}$ long and $3.6 \mathrm{~cm}$ hermaphrodite. Therefore, the relationship between male flowers and hermaphrodites, determined by environmental factors, periodically changes the age of the plant in the pomegranate, representing an evolutionary benefit of the pomegranate Wetzstein et al., (2011).

The proportion of male and female flowers in the famous Turkish variety Hicaznar has been investigated by (Gozlecki and Kaynak et al., 2000). The variations of the Hermaphrodite and male flower initiate to be the perfect flowers ranged from 13.58 to 22.32 percent. Occurs lying on recently formed branches of a similar year, often on spores or small branches about 1 month after the bud breaks.

(Wang et al., 2003 and Levin et al., 2006 and Beam home et al., 2007) While the flowers are full-grown they generate a calyx color from orange-red to dark- red that varies from species to species. The orange-red or pink petals are rarely white.

The sepals are 5 to 8 merged at base point, that forms a fleshy red vase and the sepals do not fall with the fruit collection, but remain ripe as a fundamental part of the fruit, creating a fruit in the company of a prominent calyx.

The floret has about 5 to 8 petals and their number is generally the same as the chalice number.so the petals which interchange among the sepals based on crop varieties which are divided and have a color of pinkish-orange to reddish-orange. 
The petals are upside down, fragile, and somewhat wrinkly. In a circle, the numerous lengthy stamens are inserted into the walls of the chalice and sometimes extra 300 numbers for every flower. They possess a red-orange and yellow bilocular anther joined to the essential calyx.

The nectars are positioned among the stamens along with the basal part of the ovary. The quantity of carpets varies however regularly 8 are superimposed in 2 spirals. which forms a syncarpous ovary, divided into two layers (Fahan 1976).

Point in time took for the Floral Bud creation ranges as of 19.9 to 23.5 days from CV Ganesh Persistent calyx along antheral, Sepals combined at their foundation point along stamens (top) sepals fused at foundation two sides (Dinesh Babu et al., 2011).

Flowers bud maturity stages of pomegranate are a) Stage 1 to 5 in the top row b) Stage 6 to 9 middle row c) Stage 10 to 12 bottom row Kinds of flower showing pistil type: Male flowers by elementary pistil, hermaphrodite flowers with lengthy pistil, Intermediary flower with intermediary pistil.

\section{Flowering period}

To identify the floral form and its entire characteristics, initially, we need to be familiar with the flower bloom Period/Time and it is defined as a particular period in which a flower shows its floral developmental characteristics that further enable in to form fruit. There are 3 distinct flowering seasons in subtropical, Central and Western India, i.e. Ambia Bahar (Jan-Feb), Mrig Bahar (JunJul), Hasth bahar (Sept-Oct) are followed Patil Hemanth et al., (2017).

June-July (immediately before rainy season), in Sept-Oct (very soon after completion of rainy season), and in Jan-Feb (later in wintry weather). (Patil Hemanth B et al., 2017).

Ambe Bahar is favored by growers mainly because of higher yields in comparison with other flowering seasons.

\section{Inflorescence}

It is termed as the process of flower-pattern display on plants which may be inset or cluster arrangement of flora on the main stem or side branches.

The inflorescence of pomegranate is called cymes (dichasia cyme) Flowers may look solitary, in pairs or clusters.

The solitary type flora becomes visible on spur by the side of twigs in the majority of cases, although the cluster is terminal. Appropriate to the serious fall of less important and Tertiary buds, the dichasial cyme emerges to be solitary in clusters (Dinesh babu and Chandra et al., 2011).

In the evergreen pomegranate cultivar, spring blush inflorescences bear on full-grown wood with the age of one-year-old shoots while the florets that emerge in July -Aug are formed from the recent year growth.

In deciduous cultivars, the vegetation is borne between July and August on the growth of the current season (Dinesh babu and Chandra et al., 2011).

Classification of pomegranate branches there are a total of four types of branches present including the following ones

Very long vegetative branch with big and extended leaves.

Comparatively long vegetative-reproductive branches with a single terminal flower or else more have relatively expanded leaves. 
Medium vegetative-reproductive branch with a single terminal flower or many and commonly have four small leaves.

Especially small reproductive branches employing only a single terminal flower or more

Learning about branches helps us to understand the crop vegetative status and its growing pattern which after results in reproductive growth and final outreach is the fruit

\section{Juvenility}

Here in this stage, the Plant may have a different appearance which results in the inability to form flowers in this stage and juvenility length varies from days to years

Pomegranate has a comparatively small developmental period of one year compared to various fruit crops like Berries, Guava, Sapota grafts (3years) air layered Litchi (4 years) Jack fruit (7-8 years) (Josan et al., 1979).

While saplings are brought up from seeds it, a limited ratio of them in an initial year of development set flowers and the second year bear fruit (Tera-kami et al., 2007).

The seedlings in their second or third year develop bloom and bear fruit are distinguished Punica granatum var. Nana a kind of Dwarf, can bloom and produce fruit in very young seedlings (Terakami 2007).

The time needed for seedlings to bloom by perennial plants is not generally equal to the moment in time necessary for immature plants produced by clonally propagated that is through Cutting, Grafting, Budding, and Layering. Such a way that both types of physiologically distinct cycles precedes for a comparable period in pomegranates, although the amount of time needed for blossoming differs significantly in other plants.

\section{Anthesis}

Dinesh babu et al., (2010) defined Anthesis as a particular period during which flower is fully open and functional, starts in the morning time. appearance of a split at the tip of the bud (the place where the calyx lobe join) is the initial indication of opening the flower bud, thereafter the sepals step by step separates slowly exposing the crumpled scarlet petals and begins to swell out. After full bloom corolla takes 3-4 hrs to completely open (Babu et al., 2009).

In cultivar Ganesh opening of the flower bud starts at morning 7 and finishes at evening 6 .

During the night, flower buds do not open. Maximum opening rates have been detected between 10 and 11 am (Game, 1987).

The exact time is based on the environment, the flowering cycle, and the cultivars. The optimum temperature for opening flower buds varies between cultivars. The optimal value for the Muskat White CV is between 37 and 38 degrees C (Gur, 1986).

\section{Dehiscence of the anthers}

It is stated as the final function of the anther that causes the release of pollen grains and Endothecum tissue is responsible for the splitting of anther.

Dehiscence will begin a few hours before the anthesis or much later depending on the cultivar. This is done between 7 and 15 hours later, or it can take 24 hours (Gur, 1986).

The total period depends on the cultivars and climatic conditions. Humidity and elevated temperature can accelerate dehiscence to some extent (Josan et al., 1979). 
It is possible to vary between 16,000 and 23,000 pollen grains per anther (Nath and Randhawa, 1959).

A total of $2,700,000$ pollen grains were counted from one flower (Rao and Abdul Khader, 1962). The pollens remain at 9 degrees centigrade, remain viable for 92 days, and germinate at an ambient temperature of $25^{\circ} \mathrm{C}$ (Saoji and Rudra, 1991).

\section{Receptivity of the stigma}

It is the ability of stigma which supports the germination of viable pollen. This occurs 1618 hours before anthesis and 5-6 days after anthesis

One day before the anthesis, stigmata are considered receptive. The highest receptivity is related to the time of the anthesis. Subsequently, as determined by the pollination tests, the receptivity decreases slowly and stops completely at the end of the 3rd or 5th day (Gur, 1986).

\section{Pollination}

It is the process of transport of pollen grains starting with male anther and reaching the female stigma of a flower which furthers enables to fertilization and production of seed In pomegranate both self- and crosspollination occurs but for higher fruit collection cross-pollination is preferred.

Wind pollination seems to play an insignificant role because the atmospheric pollen concentration was observed to be very small for wind pollination.

The pomegranate flowers visited by a large number of insects which include black ants, honey bees, and lemon butterflies.

In various global countries like India, Turkmen, Israel, and Tunisia different types of researches conducted on their pomegranate cultivars which show that the emasculation and bagging experiments done on flowers later pollinating them has a significant role in producing natural fruit (Levin 2006, Holland 2007).

However, it is well-known to the quantity of fruit produced through self-pollination differs between various cultivars of pomegranate (Kumar et al.2004).

In perfect blossoms, about 6 to 20 percent of pollen in male flowers can be infertile while Pollen size and fertility differ according to varieties and type of season (Morton 1987).

(Yazici 2009) showed that the higher rates of GA3 in pomegranate influenced the development of barren flora.

\section{Pollen viability and germination}

Pollen viability is the capability of pollen to carry out its role to deliver from male gametes to embryo sac after pollen release its function varies from species to species. Generally, it occurs at 2-5 days (18 - 25-degree c) and up to 6 months in a desiccator(5-degree c)

(Prakash et al., 2010) In India, the highest pollen germination rate in the start and full flowering periods were $45.8 \%$ and $42.3 \%$, respectively, in $15 \%$ sucrose.

(Üstüntaş et al., 2019) The highest germination rate $(70 \%)$ was obtained for the cultivar "Alktorshtabrizi" in agar 1,5\% + 10\% sucrose + $50 \mathrm{mg} \mathrm{L}-1 \mathrm{NAA}$ and IBA $+100 \mathrm{mg}$ L-1 boric acid (Imani and Nazarian, 2013). The highest proportion of pollen. Germination was observed as $29.1 \%$ and $19.5 \%$ in hermaphrodite and male flowers, respectively, in the start of flowering on agar $1 \%+20 \%$ sucrose +25 ppm boric acid.

Pomegranate fruits are large grains of pollen in its flowers (R Chandra Dinesh babu et al., 2011) performed research on the Ganesh 
cultivar and stated that pollen feasibility with acetocarmine stain ranged from $85 \%$ to $94 \%$. The viability of pollen is a critical event that determines the collection of fruits. Viable pollen grains were heavily stained with 1.0 percent acetocarmine while the Nonviable pollens remain unstained, 'Ganesh' pollen germination varied from 84 to 95 percent (Babu et al., 2009).

In hermaphrodite flower, the fertility of pollen grains was elevated when compared to male flowers (Nath and Randhawa1959).

The pollen grains have different sizes in the varieties tested although their common form was the alike to GB 1 was the appearance of a ring-like band was found on the pollen. These types of pollen grains are extremely productive.

Evreinoff (1957) reported Stamens production is natural, and both hermaphrodite and male flowers produce fertile pollen with a significant seasonal variability in the fertility of pollen. Specific media for the germination of synthetic pollen were checked and 12.5 percent sugar, 0.5 percent agar were known to be mainly effective and useful in favor of the phenomenon of pollen development.

\section{Heterostyly}

In this condition, the flower has different styles with different length relative to stamens of an individual type so it is a unique form with 2-3 types of flowering patterns.

Heterostyly is a popular occurrence in pomegranate, so here in this type, pin-eyed hermaphrodite florets and thrum-type staminate florets are observed.

Pomegranate flowers show signs of heterostyly which denote the incidence of two or more kinds of pistil length of flowers thus, pistils present in all three forms of florets together with staminate (male flower) is attention-grabbing. (Babu et al., 2009)

Yet the pistil is primitive in endurance bulbs and Centered on heterostyled flowers are divided into two groups like pin form (the pistil is at top position or equivalent to facilitate antheral, (ex: Androgynous blossoms) and pistil level (the pistil is smaller compared to Antherial (ex: moderate flowers).

(Babu et al., 2009) In the 'Ganesh' cultivar the measurement lengthwise of pistil was 2.00, 1.55 , and 0.65 respectively in the androgynous, intermediary, and Antheral florets.

(Karel et al., 1993) In 'Ganesh' the pistils were considerably longer than in 'Bhagwa' orby flower form, respectively, Karale et al., (1993) stated heterostyly in pomegranate

\section{Fruit}

Fruit is a fresh fleshy product of the tree or any other part of the plant which is a seedbearing structure developed from the flowering plants ovary.

At the tip of the fruit, Pomegranate has a persistent calyx. This indicates several stamens when the calyx is cut off on mature fruit. Technically the fruit is a leathery-skin type berry includes several seeds and covered by a fleshy, juicy aril. Through the ovary the fruit emerges, which is a plump berry, similarly, close-round shaped fruit has a conspicuous calyx crowned and this crown's apex is nearly closed for widespread opening, based on variety and ripening point with a smalls stalk attaches the fruit to the tree (Nath and Randhawa 1959).

There are several outstanding cultivars, including the Black pomegranate, that acquire its black type skin and stay black up to its 
maturity level. The thickness of the skin (leathery exocarp) ranges between pomegranate cultivars (Fahan 1976). The multi-ovule (locules) chamber is divided through the membranous septum and fleshy mesocarp walls. The arils produce a tasty eatable coating that grows completely based on the seed's external epidermal cells which gets longer in a radial direction to a very large degree (Fahan et al., 1976). The arils differ in thickness, and their seeds also differ in hardiness between various varieties. parthenocarpic types also produce soft seeds. The fruit matures according to the variety after 5-8 months of fruit arrangement.

A study was conducted to determine if the fruit size and production are affected by differences in flower size (Hazel $\mathrm{Y}$ et al., 2013). The flowers were hand-pollinated and the length and width of the flowers were measured and after the time of fruit was developed from the flower, then the fruit set and the size of the fruit were evaluated. On the day of pollination, 510 individual flowers (opened on that day) were used for carrying out controlled pollination. The study suggested that there was a variation in the size of the flowers and observed that the width of flowers ranged from $9.1 \mathrm{~mm}$ to $17.8 \mathrm{~mm}(1.9$ fold in the size of flower from smallest to largest). Also, the variation of length was $33.7 \mathrm{~mm}$ to $53.4 \mathrm{~mm}$ where there was a 1.6 fold increase. The variation in the size of the flower separated in terms of length and width concerning the absolute values measured. There was a similarity in the flower size distribution despite classifying them according to the length and width, however, the highest flower frequency was observed in quartile of dimension

In conclusion furthermore "Flower quality indicates that female flowers vary in size and number of ovules. Confirmation of this grade condition of flower class can have essential implications in crop yield production applications. Sex appearance in pomegranate can differ with period and time of bloom. Studies directed toward determining when male and bisexual flowers are necessary and would provide aspects into what ecological and physiological factors may be causative to sex determination in pomegranate. Optimizing cultural conditions may be a way to help the development of superior numbers of bisexual flowers with high vigorous rate to acquire maximum fruit set and yield.

\section{References}

Amasino R (2010) Seasonal and developmental timing of flowering. Plant J 61:1001-1013.

Adhikari, Subodh, Adhikari, Mahesh (2010/12/10),115 124 Floral Phenology and Pollination Ecology of Punica granatum L. in Kathmandu, Nepal 11, DO - 10.3126/njst.v11i0.4133 Nepal Journal of Science and Technology (2010).

Assaf R, Bar-Yaakov I, Fahima M, Dagan M, Hatif K (1991) Pomegranate floral biology and trials to increase productivity. Alon Hanotea 45, 461-471

Babu KD, Chandra R, Jadhav VT, Sharma J (2009) Blossom biology of pomegranate cv. 'Bhagwa' under semiarid tropics of western India. Abstract of 2nd International Symposium on Pomegranate and Minor Including Mediterranean Fruits, June 23-27, 2009, University of Agricultural Sciences, Dharwad, India, pp 88-89.

Babu, K. Dhinesh, et al., "Flower biology of pomegranate cultivar 'Ganesh' under Solapur conditions of Maharashtra-a preliminary study." Acta hortic 890 (2011): 221-226.

Buds and leaves in pomegranate (Punica granatum L.): Homa Rajaei, Parisa Yazdanpanah (2015) Phenology in relation to structure and development 
Department of Biology, College of Sciences, Shiraz University, Shiraz, 71467135.

Characteristics of flowering and fruit set of main pomegranate varieties (2016) in Montenegro Miroslav, Ranko, Mirjana Biljana, Tatjana Agriculture \& Forestry, Vol. 62 Issue 1:83-90, 2016, Podgorica 83 DOI: 10.17707/Agricult Forest. 62.1 .10

Effect of different microbial inoculants on soil properties, nutrient acquisition and growth of pomegranate (2011) Ra Marathee, Ramchandra, a Maity, J Sharma and VT Jadhav, National Research Centre on Pomegranate, Shelgi, Solapur, Maharashtra 413006

Evreinoff VA (1957) A contribution to the study of the pomegranate. Journal of Agriculture and Tropical Applied Botany 4, 124-138.

Fahan (1976) the flower. In: Plant Anatomy, Hakkibutz Hameuhad Publishers, Jerusalem, and pp 321-394.

Finland, Laukaa (2003) Research and Elite Plant Station, FIN-41330 Vihtavuori, Finland MTT Agrifood Research Finland, Plant Protection. 123-126.

Game, R.V. 1987. Studies on the floral biology of some cultivars of pomegranate (Punica granatum L.) M.Sc. Agri. Thesis, MPAU, Rahuri

Hazel Y. Wetzstein. University of Georgia, Department of Horticulture, 1111 Miller Plant Science Building, Athens, GA 30602.

Holland D, Hatib K, Bar-Yakov I, Yonay E, Abd El Hadi F (2007) 'Shani-Yonay' Pomegranate. HortScience 42, 710-711

Horticulture Journal 1959-65 Josan SS, Jawanda JS, Uppal DK (1979) Studies on the floral biology of pomegranate II. Anthesis, dehiscence, pollen studies, and receptivity of stigma.Punjab Horticulture Journal 19, 66-70.

Horticulture Statistics (2018) Division,
Department of Agriculture, Coopn \& Farmers Welfare including Mediterranean Fruits, University of Agricultural Science, Dharwad, India, June23-27, (2009), 108-109.

Josan SS, Jawanda JS, Uppal DK (1979a) Studies on floral biology of pomegranate I. Flowering habit, bud development and floral morphology. Punjab. Punjab Res. Journal. 112-114

Jyotsana Sharma, D.T. Meshram, Ashis Maity, D.T. Chaudhari, S.S.Wadne, and K. Dinesh Babu (2018). 'Pomegranate: a Crop for Doubling Farmers IncomeSuccess Stories of Farmers ICARNRCP e-Publication 2018/2.

Karale AR, Supe VS, Kaulgud SN, Kale PN (1993) Pollination and fruit set studies in pomegranate. Journal of Maharashtra Agriculture University 18, 364-366.

Komeda Y (2004). Genetic regulation of time to flower in Arabidopsis thaliana. Annu Rev Plant Biol 55:521-535.

Kumar R, Jayesh KC, Kumar R (2004) Crossability in pomegranate (Punica granatum L.) Indian Journal of Horticulture 61, 209-210.

Levin GM (1978) the floral biology of pomegranate (Punica granatum L.) in south-west Turkmenistan. Turkmenistan SSR Ylymlar Akademijasynyn Habarlary Biologik Ylymlaryn 5, 31-38.

Levin GM (1995) Aspects of pomegranate culture in Turkmenistan. Plant genetic Resources Newsletter 97, 31-36.

Levin GM (2006) Pomegranate Roads: A Soviet Botanist's Exile from Eden (IST Edn), Floreat Press, Forestville, CA, pp 15-183.

Microbial inoculation for improving the growth and health of micro propagated strawberry (2004) M. Vestberg a, S. Kukkonen a, K. Saari a, P. Parikka b, J. Huttunen c, L. Tainio c, N. Devos d, F. Weekers d, C. Keversd, P. Thonart d, 
Lemoin e, Cordier f, C. Alabouvette, S. Gianinazzi fa MTT Agrifood Research. 119-136.

Miguel MG, Neves MA, Antunes MD (2010) Pomegranate (Punica granatumL.): a medicinal plant with myriad biological properties - A short review. J Med Plants Res 4:2836-2847.

Nalawadi VG, Farooqui AA, Dasgupta N, Reddy MA, Gubbaiah Sulikeri GS, Nalini AS (1973) Studies on the floral biology of pomegranate (Punica granatum L.). Mysore Journal of Agricultural Science 7, 213-225

Nath N, Randhawa GS (1959, 1) Classification and description of some varieties of Punica granatum L. Indian Journal of Horticulture 16, 191-200

Nath N, Randhawa GS $(1959,2)$ Studies on the floral biology of pomegranate. II.Anthesis, dehiscence, pollen studies, and receptivity of stigma. Indian Journal of Horticulture 16, 121-135

Nath N, Randhawa GS (1959, 3) Studies on floral biology in the pomegranate (Punica granatum L.). III. Pollination, fruit-set, and seed formation. Indian Journal of Horticulture 16, 136-140

Patil, Hemant B., et al., "Characterization of two Terminal flowering 1 homologs PgTFL1 and PgCENa from pomegranate (Punica granatum L.). Tree Physiology 38.5 (2018): 772-784.

Prakash A, Chauhan S, Rana A, Chaudhary V (2010). Study of in vitro pollen germination and pollen viability in Punica granatum L. (Punicaceae). Research Journal of Agricultural Sciences 1(3): 224-226.

Pomegranate: Cultivation, Marketing, and Utilization. Technical Bulletin No. NRCP/2014/. ICAR-National Research Centre on Pomegranate, Solapur- 413 255 (Maharashtra).

Rao, V. N. M., and Abdul Khader, J.B.M. (1962). Estimation of pollen production in fruit crops. Madras Agric. J., 49: 152-166.

Singh, Thiyam Jefferson, et al., "Reproductive biology and breeding system of pomegranate: A Review." Journal of progressive horticulture" 7.1 (2016): 9-16.

Saoji, A. A., and Rudra, J. 1991.Estimation of protein contents in the stored pollen grains of P.granatum L., Ad. Plant in Plant Sci., 4 (2): 316-318

Sharma Jyotsana., Babu, K.D., Maity, A., Singh, N.V. and Gaikwad, N. 2018. ICAR-NRCP Annual Report 2017-18, ICAR-NRCP, Solapur, p. 126.

Singh SS, Krishnamurthi S, Katyal SL (1967) Fruit Culture in India, Indian Council of Agricultural Research, New Delhi, pp 207-214.

Srikanth A, Schmid M (2011) Regulation of flowering time: all roads lead to Rome. Cell Mol Life Sci 68:2013-2037.

Teixeira da Silva JA, Rana TS, Narzary D, Verma N, Meshram DT, Ranade SA (2013) Pomegranate biology and biotechnology: a review. Sci Hortic 160:85-107

Terakami, S., Matsuta, N. Yamamoto, T. Sugaya, S. Gemma, H., and J. Soejima, $2007 . \quad$ Agrobacterium-mediated transformation of the dwarf pomegranate (Punica granatum L. var. nana). Plant Cell Rep., 26: 1243-1251.

Üstüntaş T, Dalkılıç Z, Günver Dalkılıç G (2019). Effect of stigma exudate on pollen germination in pomegranate. Acta Horticulturae 1254:109-114.

Wetzstein, Hazel Y., et al., "Flower position and size impact ovule number per flower, fruit set, and fruit size in pomegranate."Journal of the American Society for horticultural science 138.3 (2013): 159-166.

Wetzstein, H.Y., Ravid, N., Wilkins, E., Martinelli, P. Adriana (2011): A morphological and histological 
characterization of bisexual and male flower types in pomegranate. Journal of the American Society for Horticultural Science, 136(2), 83-92.

Yazici K, Ulger S, Kaynak L (2009) the relationship between flower development and endogenous gibberellins in pomegranate cv. 'Hicaznar'. International Symposium on Pomegranate and Minor. 1878-1887

\section{How to cite this article:}

Varun Kumar, N., Ankush Godara and Anis Mirza. 2020. Characteristics of Flowering and Fruiting Description of Pomegranate (Punica granatum L.). Int.J.Curr.Microbiol.App.Sci. 9(11): 401-412. doi: https://doi.org/10.20546/ijcmas.2020.911.049 